\section{Diagnostic Nutrient Testing}

\author{
R.S. Mylavarapu ${ }^{1}$
}

AdDITIONAL INDEX WORDs. BMP, soil fertility, water quality, NIR spectroscopy

SUMMARY. Recommendations made for nutrient applications have traditionally focused on economic yield and quality. However, present-day testing procedures and recommendations are required to simultaneously ensure economical and environmental sustainability of agricultural production systems. A soil test is a calibrated index relating crop response to applied nutrients. Any application rate devoid of an economical response in yield or quality is deemed unnecessary. Therefore, a soil test becomes the first step in any nutrient best management practice (BMP) development, implementation, and monitoring activity. Certain significant areas in Florida, such as calcareous soils, require development of calibrated soil tests rather urgently. Nutrient sufficiency of perennial crops and deficiency diagnostics can be gauged through in-season plant tissue testing. Nutrient delivery for correcting the deficiency through foliar sprays is not always effective, and may require multiple applications. Spectral reflectance methods show significant promise as an alternative to traditional wet chemistry analyses with regard to ease, costs, and speed with wider range of applications, including natural resources. Additional research is needed to develop this technology for field-scale applications. Current research is focusing on environmental nutrient management to include nutrient sources, application rates and timing, nutrient uptake efficiency, retention capacity of soils, estimating and minimizing nutrient losses to the environment, etc.

Nutrient loss assessments tools such as the Florida phosphorus $(P)$ index and bahia (Paspalum notatum) and citrus (Citrus spp.) tests for $\mathbf{P}$ are now being made possible in Florida through integration of soil and tissue testing methods. Development and improvements of such analytical methods and tools specific to Florida to include other nutrients, heavy metals, soil capacity, and ecosensitive regions, is vital to ensure sustainability to the state's tourism, agriculture, and urban-rural balance.

$\mathrm{H}$ igh-quality diagnostic soil, plant, and water-testing programs are required to achieve optimum agricultural production and to minimize negative environmental impacts. While soil fertility assessments and field-calibrated nutrient recommendations have been tremendously successful during the past half-century, resulting in self-reliance in food production and food security, the presentday diagnostic testing programs require sophisticated instrumentation and methods to simultaneously ensure environmental sustainability of nutrient cycling through rural and urban agricultural operations and natural ecosystems.

The primary objective of traditional soil- and plant-testing programs is to estimate the nutrient supplying capacities of various soil types and consequently to provide calibrated recommendations for fertilizer management such that long-term agricultural production efficiency is maintained and sustainable and rational utilization

Department of Soil and Water Science, Institute of Food and Agricultural Sciences, University of Florida, Gainesville, FL 32611

${ }^{1}$ Corresponding author. E-mail: raom@ufl.edu. of soil resources is achieved. Soils differ considerably from season to season in their capacity to provide for the nutritional needs of crops. A scientific approach involves determination and elimination of soil nutrient constraints for a balanced supply of essential nutrients for optimum yields. In addition, soil tests are used to monitor the impact of past fertility practices on changes in the soil nutrient status. The recommendations are made based on the results from analytical tests done on soil, plant tissue, and sap, and subsequent crop response. The main disadvantage of a fertilizer management program is that it is very crop specific and hence cannot be extrapolated to other situations for the improvement of nutrient recommendations. This major drawback had led to the use of remote sensing techniques that estimate micronutrient availability on a fundamental basis so that fertilizer management recommendations can be used on different soils types in different regions.

\section{Soil testing}

Soil testing is a multistep process starting with the collection of a sample. The sample has to be a true representative of the area. Test results and recommendations will be only as good as the sample. The need for an appropriate representative sample can never be overemphasized. In the laboratory, the first step is extraction or digestion of the sample. The method employed is specific to the nutrients, the geographic region, and the physiographic and mineralogical nature of the sampling site. Therefore, multiple methods exist. In Florida, we have four methods for three major groups of soils. Interpretation of the test results for the intended application is the second and most important step in the entire process. State laboratories backed by nutrient management and environmental quality research information make the process credible. Once the test results are interpreted, nutrient recommendations are formulated based on the fieldcalibrated crop response. A separate soil $\mathrm{pH}$ and lime requirement determination is also made to ensure effective soil $\mathrm{pH}$ management as per the target $\mathrm{pH}$ specific to the crop being grown. In addition to the soil test results and recommendations, several footnotes are also included in the reports, providing tips on the split doses, rates, timing, irrigation, and other management practices, and those footnotes form an integral part of the recommendations.

While the extent of adoption of soil test recommendations is probably governed by socioeconomic factors, there are some limitations to the traditional diagnostic soil testing process. Soil testing is time consuming and, in certain cases, expensive. A soil test cannot prevent poor crop growth due to drought, disease, insects, too much water, pesticide residues, etc. Additionally, in the absence of regular field calibrations of recommendations for new varieties, new crop species,

\begin{tabular}{llll}
\hline $\begin{array}{l}\text { Units } \\
\begin{array}{l}\text { To convert U.S. to SI, } \\
\text { multiply by }\end{array}\end{array}$ & U.S. unit & SI unit & $\begin{array}{l}\text { To convert SI to U.S., } \\
\text { multiply by }\end{array}$ \\
\hline 0.4047 & acre(s) & ha & 2.4711
\end{tabular}

\footnotetext{
Chatednolog $\cdot$ February $201020(1)$
}

0.4


new nutrient sources, micronutrients, altered management practices, new analytical methods and reagents, etc., the viability of soil testing will be limited. The lack of a reliable soil test for estimating nitrogen $(\mathrm{N})$ availability is a serious disadvantage, given that the plant uptake efficiency of applied fertilizer $\mathrm{N}$ is only $30 \%$ to $50 \%$ (Raun and Johnson, 1999). Sandy soils in Florida, combined with high temperature and rainfall, increase the potential for $\mathrm{N}$ loss significantly. Integration of nutrient and irrigation management recommendations is the critical need of the hour, particularly for our soils and intensive production practices.

\section{Plant tissue testing}

Plant analysis is a proven and effective means of predicting fertilizer needs for many crops, especially perennial crops, although it does not completely replace a soil test. Soil and plant diagnostics are complementary and serve different purposes. Plant tissue tests help monitor the nutrient status of plants throughout the growing season to determine whether each nutrient is present in sufficient concentrations for optimum growth characteristics. The tissue tests confirm suspected nutrient deficiency symptoms, reveal hidden hunger, and verify toxicities. Plants may not show any visible symptoms, but the nutrient content maybe insufficient to reduce the yields. In-season corrections to nutrient deficiencies can be made through foliar applications of specific deficient nutrients. Tissue tests also indirectly aid in evaluating the efficiency of applied fertilizers.

\section{Why test soil and plant tissue?}

Soil testing indirectly estimates the amount of nutrients present and, in turn, the portions of those soil nutrients that will be available to the crop during the growing period. Leaf diagnosis shows the nutrient status of the plant at the particular time of sampling. However, leaf diagnosis alone may not give an accurate picture of nutrient requirements. Soil nutrient levels are only one of many factors that determine the nutritional status of a plant. Other factors such as temperature, water availability, and management factors also influence soil fertility status, nutrient balance, etc. Due to such complexity, leaf analysis has to be integrated with soil analysis. In Florida, two such new tests have been developed and implemented: for bahia pastures (Mylavarapu et al., 2007a) and commercial citrus. In both tests, the $\mathrm{P}$ requirement is determined by a combination of a soil and plant tissue test and deficiency confirmation.

Collection of foliar samples for nutrient analyses is critical to the success of a nutrient management program. Each sample should be collected so that leaflets come from representative plants over the entire sample area (Southern Extension and Research Activity-Information Exchange Group-6, 2000). Sampling should be done from the proper plant part at the proper growth stage. For young seedlings, the entire plant is sampled 1 inch above the soil level. For larger plants, the most recent fully developed and mature leaf is the best indicator of nutritional status. For certain crops, including corn ( $\mathrm{Zea}$ mays), the best indicator of nutritional status is the leaf adjacent to the uppermost fruit (ear leaf), when it approaches the flowering stage. When unfamiliar with sampling protocol for a specific crop, it is generally acceptable to select the most recent mature leaf as the best indicator of nutritional status. Insect- and disease-damaged leaflets, and leaflets showing severe deficiency symptoms, should be avoided or should be sampled separately (Herrera, 2005).

\section{Plant sap testing}

Analysis of plant sap measures mobile nutrients in the plant system, thus providing a different view of plant nutrition than the traditional dry tissue analysis. Sap testing is more sensitive and therefore can detect minor or temporary deficiencies more easily. An accurate diagnosis of plant stress is possible and thus effective management decisions to correct nutrient imbalances or deficiencies can be made. Sap testing is useful for monitoring the effectiveness of fertilizer application, plant stress due to $\mathrm{N}$ and potassium $(\mathrm{K})$, etc.

Temperature and time of the day are shown to influence plant sap nitrate content. Taking readings consistently between 0900 and $1600 \mathrm{HR}$ will yield the most consistent results (Hochmuth, 2003). Sap samples are usually taken from petioles of the most recently matured leaves. Although three or four petioles may produce a sufficient amount of sap for testing, additional plants must be sampled to ensure that the sap sample is representative of the field or area being tested. In a uniform field, about 20 leaves should be sampled to adequately represent a 5- to 10 -acre area. The petioles should be chopped and mixed, and a subsample of the chopped petiole pieces should be used for the final sample to crush (Hochmuth, 2003). Vegetable crops grown in Florida under intensive management can benefit from sap testing and nutrient monitoring. The frequency and consistency required for sampling, and the validity of the procedure for only mobile nutrients such as $\mathrm{N}$ and $\mathrm{K}$, result in limited application of the procedure.

\section{Remote sensing techniques: Near-infrared spectroscopy (NIRS)}

Near-infrared (NIR) spectroscopic technique is a multistep process (Fig. 1) that enables rapid and nondestructive analytical correlation of diffusely reflected NIR radiation with chemical and physical properties of soil and plant components. It identifies chemical compounds based on the differential absorption of infrared light at different wavelengths depending upon the nature of the particular chemical functional group. When white light strikes the surface of soil/ plants, it is reflected in wavelengths that have a characteristic frequency and energy based on the chemical composition of soil/plants. The reflected light from the sample surface is measured by a spectrophotometer. While the current technology allows for the use of this technology in the laboratory, sensors are being developed for on-the-go measurement of soil properties with the potential to provide benefits from the increased density of measurements at a relatively low cost (Adamchuk et al., 2004).

\section{Why should NIRS replace wet chemistry analysis?}

With the advancement of technology, many soil and plant analyses can now be carried out rapidly using automated laboratory equipment such as an autoanalyzer and inductively 


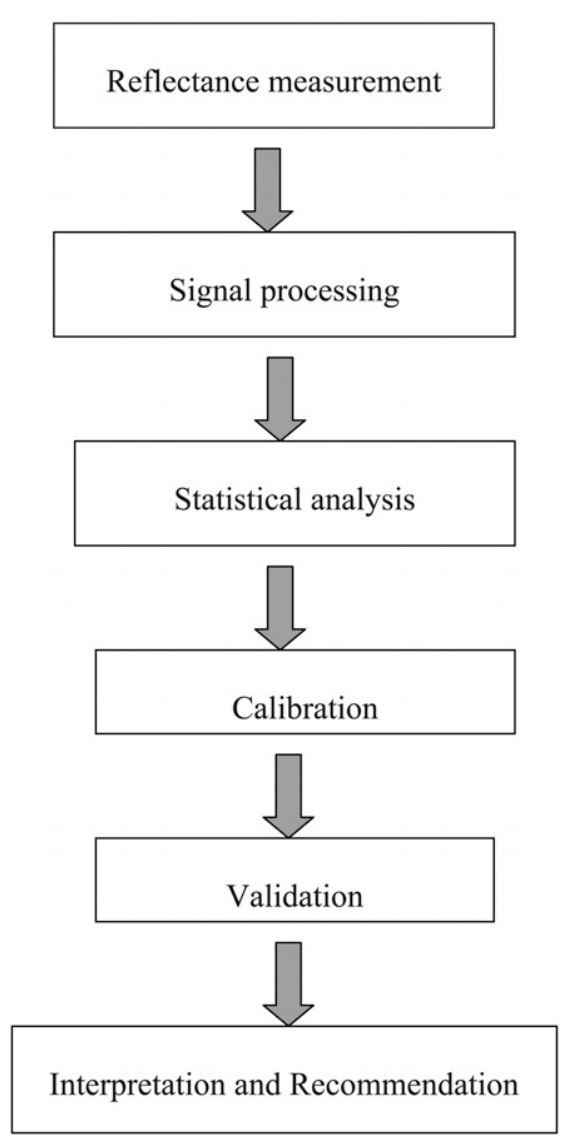

Fig. 1. The sequence of steps that should be followed for implementing the near-IR spectroscopic technique as a successful diagnostic nutrient testing tool.

coupled plasma (ICP) spectrometer. Each property or concentration has a specific level of energy, and the instruments capture the wavelength of that specific light energy, similar to the NIR technique. Determinations are done indirectly, calibrated, validated, and interpreted through indices.

Analysis of soil and plant tissue samples using NIRS can provide compositional information of every sample within the time frame and cost of a single determination. The NIRS technique is rapid, instantaneous, nondestructive, cheap, portable, and has a wide variety of applications such as routine soil analysis, soil property classification, soil survey and mapping, precision agriculture, diagnosis of soil problems, contaminated site characterization, input data for models, decision support, etc.

The NIR radiation is not merely reflected from the outside surface, but actually penetrates the sample. Each time a chemical bond is encountered that does not absorb the particular wavelength, the rays are scattered and reflected in all directions. These scattered beams may then be absorbed or reflected by other chemical bonds until a portion of the rays eventually exits the sample in all directions. The reflected rays then are concentrated onto a measuring cell. The number of reflections at different wavelengths are measured and then converted to analytical results by a microprocessor.

Three major research projects in Florida have been funded to develop fundamental relationships between soil properties from representative soil orders in Florida and the spectral characteristics of the soil samples, as a preliminary step toward development of a real-time soil property sensor for use in site-specific crop management. The sensor system could eventually contribute to efficient water and nutrient management for economically viable agricultural production and natural resources protection and preservation. Soil $\mathrm{pH}$, organic matter, and nutrient content were studied in 90 soil samples each collected from Alfisols, Entisols, and Ultisols (Lee et al., 2003). The partial least squares procedure predicted $79 \%$ of the variation in soil $\mathrm{pH}, \mathrm{P}$, calcium (Ca), and magnesium ( $\mathrm{Mg}$ ) for Alfisols, Entisols, and Ultisols of Florida.

In another study (Cohen et al., 2007), a set of 1933 samples, representative of major soil orders in Florida, was assembled from samples submitted to the Institute of Food and Agricultural Sciences (IFAS) Extension Soil Testing Laboratory (ESTL) for routine testing during 2004-05. High-resolution diffuse reflectance spectra of each soil in the visible and near infrared regions were used to predict observations using standard laboratory analytical procedures for soil pH, Mehlich-1 (M-1) extractable $\mathrm{P}, \mathrm{K}$, Ca, $\mathrm{Mg}$, copper $(\mathrm{Cu})$, manganese (Mn) and zinc $(\mathrm{Zn})$, aluminum $(\mathrm{Al})$, percentage of organic matter (OM), and saturated hydraulic conductivity (Ksat). The following results highlight some of the conclusions from the study:

- M-l Al, Ca, Mg, and P were predicted more effectively from spectra, and generally had higher concentrations in the soils that were analyzed.

- Analytes with higher concentrations were more predictable than those with lower concentrations.
- The relatively high prediction efficiency for $\mathrm{Mg}$ is presumably due to its correlation with $\mathrm{Ca}$.

- The relatively high regression point displacement (RPD) for P might have been a result of correlation with $\mathrm{Al}$ and $\mathrm{Ca}$, both of which were effectively predicted.

- Model efficiency was observed to be positively associated with mean analyte concentration.

- Categorical modeling (threshold-based classes) was successful for pH, M-1 P, Mg, and Ksat.

- In addition, categorical condition for analytes where continuous prediction was insufficient $(\mathrm{M}-1, \mathrm{Cu}$, and $\mathrm{Mn}$ ) was successfully diagnosed.

Predictions of $\mathrm{M}-1, \mathrm{~K}$, and $\mathrm{Zn}$ categories were statistically significant, but of insufficient accuracy to be of diagnostic utility.

In an on-going third study, a sample set consisting of 1000 soil and corresponding 1000 tissue samples is being collected from throughout the state (Mylavarapu et al., 2007b). Commodities targeted are forages, vegetables, peanuts (Arachis hypogaea), and citrus. Soil and leaf tissue reflectance will be correlated. A subset of soil samples was used to determine the influence of multiple moisture levels. Soil texture will also be determined for a subset of soil samples.

The NIR technique is very promising, and with the availability of new robust statistical techniques, the calibration with wet-chemistry test results can be improved. However, the real-time sensors and field application of the technology is a few years away.

\section{Diagnostic testing and environmental assessment}

This is the most critical current need in the area of nutrient management. The need to generate new knowledge to bridge the gap between diagnostic testing for agronomic production and environmental impact assessment is immense. Traditional soil fertility research has been revamped into nutrient management to accomplish this goal. Typically, multiple factors influence the fate of the nutrients and nutrient cycling in the natural and agricultural systems. Anthropogenic factors only enhance the cycling rates. In Florida, such tools have been developed and are being fine-tuned. 
For example, a simple routine soil test is adequate to estimate the plant-available $\mathrm{P}$ in the soils. However, other factors that affect the $\mathrm{P}$ movement, adsorption, retention, and release in soils have been compiled along with site management factors into a tool called the Florida P index (PI; Hurt et al., 2006). Although currently intended for sites that receive organic sources of nutrients, the PI can be applied to any situation where nutrients, particularly, are applied. The potential for offsite movement of applied P can be qualitatively determined. The revised PI will include a test to determine P retention capacity of the soils by determining the ratio of the concentrations of extractable iron $(\mathrm{Fe}), \mathrm{Al}$, and $P$. The IFAS ESTL will be offering a new PI test for this step using the following computation: Capacity in$\operatorname{dex}=\{0.1-[$ (soil test $\mathrm{P} / 31) /($ soil test $\mathrm{Fe} / 56)+($ soil test $\mathrm{Al} / 27)]\} \times[($ soil test $\mathrm{Fe} / 56)+($ soil test $\mathrm{Al} / 27)] \times 31$. This equation determines the relative concentrations of $\mathrm{P}, \mathrm{Fe}$, and $\mathrm{Al}$ in the soils and estimates $\mathrm{P}$ retention capacity by $\mathrm{Fe}$ and $\mathrm{Al}$ present in the soil.

Similarly, development of combined soil and plant tissue tests for determining the need for $\mathrm{P}$ application has been an effective tool in determining the true $\mathrm{P}$ requirement of perennial crops and consequently minimizing environmental losses. Two new soil and tissue tests for determining the $\mathrm{P}$ requirement for bahia pastures and commercial citrus producers are being offered at the IFAS ESTL. Similar models for $\mathrm{N}$ and heavy metals can be developed.

\section{Research priorities}

- Develop, calibrate, and establish a valid soil extraction procedure for nutrient recommendations for calcareous soils, a major soil category for commercial and urban landscape horticulture in the state.

- Validate the PI, a critical tool for $\mathrm{P}$ management, particularly when organic sources are used and for various sensitive ecosystems in the state.

- Develop a tool for $\mathrm{N}$ management to assess plant uptake efficiency and environmental loss.

- Determine the feasibility of complementary soil and tissue analyses for $\mathrm{P}$ management for perennial crops and landscape plants and grasses.

- Integrate recommendations for irrigation management with nutrient recommendations for commercial horticultural crops.

- Further develop NIR techniques and continue field calibration for wider diagnostic applications.

- Develop newer diagnostic techniques for environmental impact assessment.

\section{Literature cited}

Adamchuk, V.I., J.W. Hummel, M.T Morgan, and S.K. Upadhyaya. 2004. On-the-go soil sensors for precision agriculture. Comput. Electron. Agr. 44:7191.

Cohen, M., R.S. Mylavarapu, W.S. Lee, and M. Clark. 2007. Reflectance spectroscopy for routine agronomic soil analyses. Soil Sci. 172:469-485.

Herrera, E. 2005. Sampling pecan leaves for analysis guide. New Mexico State Univ., College Agr. Home Econ., Guide
H-619 PH 4-102, 25 Aug. 2009. <http:// cahe.nmsu.edu/pubs/_h/h-619.html>.

Hochmuth, G. 2003. Plant petiole saptesting for vegetable crops. Univ. Florida, Inst. Food Agr. Sci., Coop. Ext. Serv., Dept. Hort. Sci., Ext. Circ. 144.

Hurt, G.W., R.S. Mylavarapu, and S.P. Boetger. 2006. UF/IFAS Nutrient Management Series: Computational tools for field implementation of the Florida $\mathrm{P}$ index-St. Johns County Florida. Univ. Florida, Inst. Food Agr. Sci., Coop. Ext. Serv., Dept. Soil Water Sci. CIRCULAR 1331,19 p.

Lee, W.S., J.F. Sanchez, R.S. Mylavarapu, and J.S. Choe. 2003. Estimating chemical properties of Florida soils using spectral reflectance. Trans. Amer. Soc. Agr. Eng. 46:1443-1453.

Mylavarapu, R.S., A.W. Schumann, T.A. Obreza, and C. Cornejo. 2007b. Rapid soil and tissue analysis techniques using near infrared reflectance spectroscopy. Project 61580 annual report. Florida Dept. Agr. Consumer Serv., Tallahasee, FL.

Mylavarapu, R.S., D. Wright, G. Kidder, and C.G. Chambliss. 2007a. UF/IFAS standardized fertilization recommendations for agronomic crops. Univ. Florida, Inst. Food Agr. Sci., Coop. Ext. Serv., Dept. Soil Water Sci., SLl29.

Raun, W.R. and G.V. Johnson. 1999. Improving $\mathrm{N}$ efficiency for cereal production. Agron. J. 91:357-363.

Southern Region Extension and Research Activities Information Exchange Group6. 2000. Reference sufficiency ranges for plant analysis in the southern region of the United States. C.R. Campbell (ed.). North Carolina Dept. Agr., Agronomic Div., Southern Reg. Coop. Ser. Bul. No. 394, 25 Aug. 2009. <http://www.agr. state.nc.us/agronomi/saaesd/scsb394. htm>. 